\title{
Skeletal Muscle Volume and Intramuscular Adipose Tissue Are Prognostic Predictors of Postoperative Complications After Hepatic Resection
}

\author{
NORIFUMI HARIMOTO, HIROKI HOSHINO, RYO MURANUSHI, KEI HAGIWARA, \\ TAKAHIRO YAMANAKA, NORIHIRO ISHII, MARIKO TSUKAGOSHI, TAKAMICHI IGARASHI, \\ AKIRA WATANABE, NORIO KUBO, KENICHIROU ARAKI and KEN SHIRABE \\ Department of Hepatobiliary and Pancreatic Surgery, \\ Graduate School of Medicine, Gunma University, Maebashi, Japan
}

\begin{abstract}
Background/Aim: Recently, skeletal muscle quality was important in patients with malignant tumors to predict the surgical outcome. The relationship between postoperative complications of Clavien-Dindo grade III or more and prognosis in patients who have undergone hepatic resection for hepatic malignancies were investigated. Patients and Methods: Patient data were retrospectively collected for 146 consecutive patients who underwent curative hepatic resection in the Department of Hepatobiliary and Pancreatic Surgery, Gunma University, Japan, for hepatic malignancy. The patients were assigned to two groups according to the presence of postoperative complications. The clinicopathological and surgical outcomes were analyzed. Skeletal muscle area (SMA) and intramuscular adipose tissue content (IMAC) were also evaluated. Results: No hospital deaths occurred. Postoperative complications were identified in 12 patients (8.2\%). Univariate and multivariate analyses revealed that the independent risk factors for postoperative complications were hemodialysis, psychiatric disorder, high CONUT (controlling nutritional status) score and patients both with low SMA and high IMAC. Conclusion: Intensive surgical care is necessary for high-risk patients with hemodialysis, psychiatric disorder, high CONUT count and/or low skeletal muscle quality to reduce postoperative complication.
\end{abstract}

Correspondence to: Norifumi Harimoto, MD, Department of Hepatobiliary and Pancreatic Surgery, Graduate School of Medicine, Gunma University, 3-39-22, Showamachi, Maebashi, 371-8511, Japan. Tel: +81 272208224, Fax: +81 272208224, e-mail: nharimotoh1@gunma-u.ac.jp

Key Words: Intramuscular adipose tissue, complication, hepatic resection.
Postoperative complications may lead to systemic inflammation and there is increasing evidence that increased systemic inflammation correlates with adverse effects on the short- and long-term outcomes of various cancers (1-7). Additionally, postoperative complications are distressing for patients and medical staff and lead to higher medical costs. Hepatic resection was previously thought to be dangerous because of a bleeding tendency or liver dysfunction. We previously reported that postoperative complications were identified in $17.1 \%$ of patients who have undergone hepatic resection for hepatocellular carcinoma (2). Although recently, improvements in operative methods and perioperative care have decreased morbidity and mortality rates $(3,4)$, relatively high morbidity rates associated with hepatic resection remain problematic. Therefore, identification of predictors of post-hepatic resection complications is needed.

Recently, sarcopenia is reported not only to be a predictor of morbidity but has been found to be a predictor of poor prognosis in patients with many cancers (8-13). Sarcopenia is a syndrome characterized by the progressive and generalized loss of skeletal muscle mass and strength, accompanied by an increased risk of adverse outcomes such as physical disability, poor quality of life, and death $(14,15)$. In 2010, the European Working Group on Sarcopenia in Older People (EWGSOP) published a clinical definition of and consensus diagnostic criteria for sarcopenia, and proposed an algorithm evaluating muscle strength and physical performance, in addition to skeletal muscle mass volume, which means that both skeletal muscle volume and quality are important (16).

The method of evaluating the quality of muscle includes many different ways such as hand grip strength, gait speed or intramuscular adipose tissue content (IMAC) (17-20). Especially, intramuscular adipose tissue content is reported to be a significant predictor of both muscle function and mobility function in older adults (17). IMAC was also used 
widely to evaluate the low-quality of skeletal muscle in many cancers, which leads to predictive marker of survival or morbidity. IMAC can be measured easily and retrospectively.

A retrospective study was performed to investigate the short-term outcomes of patients with postoperative complications who had undergone hepatic resection for hepatic malignancy including hepatocellular carcinoma (HCC), cholangiocellular carcinoma (CCC), metastatic liver cancer and biliary cancer. Skeletal muscle area (SMA) and IMAC were also evaluated.

\section{Patients and Methods}

Patient characteristics. Patient data were retrospectively collected for 146 consecutive patients who underwent curative hepatic resection in the Department of Hepatobiliary and Pancreatic Surgery, Gunma University, Japan for hepatic malignancy with between January 2016 and December 2017. In this period, perioperative management was standardized by one team. The hepatic resection combined with biliary reconstruction or anastomosis of digestive tract were excluded. The patients were assigned to two groups according to the presence of postoperative complications. The clinicopathological and surgical outcome were analyzed. Postoperative complications were defined by ClavienDindo grade III or more (those which require surgical intervention) within 1 month of hepatectomy (21).

A transverse CT scan of the third lumbar vertebrae (L3) in the inferior direction was used to identify and quantify skeletal muscle by Hounsfield unit (HU) thresholds of -29 to +150 , with water and air having HUs of 0 and 1000, respectively. Muscles identified included the psoas, erector spinae, quadratus lumborum, transversus abdominis, external and internal obliques, and rectus abdominis muscles. The cross-sectional areas $\left(\mathrm{cm}^{2}\right)$ of skeletal muscles in the L3 region were measured by manual outlining on the CT images according to the previous report $(8,9)$. SMA was calculated by dividing the cross-sectional areas $\left(\mathrm{cm}^{2}\right)$ of skeletal muscle with the height $\left(\mathrm{m}^{2}\right)$ and was defined as low in patients with less than $42 \mathrm{~cm}^{2} / \mathrm{m}^{2}$ in men and less than $38 \mathrm{~cm}^{2} / \mathrm{m}^{2} \mathrm{~kg}$ in women according to the guideline of sarcopenia (22). IMAC was calculated by dividing the $\mathrm{CT}$ value of the multifidus muscles with the $\mathrm{CT}$ value of subcutaneous fat according to the previous report (10-13). The optimal cut-off values of IMAC were determined for men and women separately using receiver operating characteristic curves. IMAC was defined as high in patients with higher than -0.730 in men and higher than -0.502 in women.

Preoperative controlling nutritional status (CONUT) scores were calculated based on serum albumin concentrations, peripheral lymphocyte counts, and total cholesterol concentrations $(23,24)$. [1] Albumin concentrations $\geq 3.5 \mathrm{~g} / \mathrm{dl}, 3.0-3.49 \mathrm{~g} / \mathrm{dl}, 2.5-2.99 \mathrm{~g} / \mathrm{dl}$, and $<2.5 \mathrm{~g} / \mathrm{dl}$ were scored as $0,2,4$, and 6 points, respectively. [2] Total lymphocyte counts $\geq 1,600 / \mathrm{mm}^{3}, 1,200-1599 / \mathrm{mm}^{3}, 800-1199 / \mathrm{mm}^{3}$, and $<800 / \mathrm{mm}^{3}$ were scored as $0,1,2$, and 3 points, respectively. [3] Total cholesterol concentrations $\geq 180 \mathrm{mg} / \mathrm{dl}, 140-179 \mathrm{mg} / \mathrm{dl}, 100-$ $139 \mathrm{mg} / \mathrm{dl}$, and $<100 \mathrm{mg} / \mathrm{dl}$ were scored as $0,1,2$ and 3 points, respectively. The CONUT score was defined as the sum of [1], [2], and [3].

Patients with diabetes were defined as those using oral hypoglycemic agents or insulin.
Surgical procedures. The details of the surgical techniques and patient selection criteria have been reported previously (25). Our criteria for hepatic resection were that ascites was not detected or was controllable by diuretics; serum total bilirubin level was $<2.0 \mathrm{mg} / \mathrm{ml}$; and the $\mathrm{ICGR}_{15}$ value was less than $40 \%$. The surgical procedure comprised making a $\mathrm{J}$-shaped incision for routine abdominal access, slow and gentle hepatic dissection using an ultrasonic dissector with a coagulator (CUSA Excel; Integra, USA), systematic ligation of all sizable vessels, and close ultrasonographic guidance along the transection line. Intraoperative vascular control was achieved by the Pringle maneuver (26).

Histological study. All of the resected specimens were cut into serial 5- to $10-\mathrm{mm}$-thick slices and fixed in $10 \%$ formalin. After macroscopic examination, the biggest slice was trimmed for embedding in paraffin and cut into $4-\mu \mathrm{m}$ sections for microscopy. The sections were stained with hematoxylin and eosin. The histological diagnosis was assessed by the pathologist.

Statistical analysis. The associations of continuous and categorical variables with the relevant outcome variables were assessed using the Student's $t$-test and the $\mathrm{x}^{2}$ test, respectively. A logistic stepwise regression analysis to predict the presence of postoperative complication was performed with variables displaying a $p$-value less than 0.05 in univariate analyses. The serum albumin level and creatinine were excluded for a logistic stepwise regression analysis because these were confounding factors for CONUT score and hemodialysis, respectively.

All analyses were performed with Statview 5.0 software (Abacus Concepts, Berkeley, CA, USA). A $p$-value less than 0.05 was considered statistically significant.

\section{Results}

Clinical characteristics of patients with hepatic resection are shown in Table I. No hospital deaths occurred. Median blood loss was $167 \mathrm{ml}$ during surgery. Postoperative complications were identified in 12 patients $(8.2 \%)$. Mean patients age was 68 years old, and patients aged 80 years and older were $12.3 \%$ $(n=18)$. High age $(\geq 80)$ was not a significant risk factor of postoperative complication. Univariate and multivariate analyses revealed that the independent risk factors for postoperative complications were hemodialysis, psychiatric disorder, high CONUT (controlling nutrition status) count and patients both with low SMA and high IMAC. Postoperative complications were identified in 7 cases among 39 patients with both low SMA and high IMAC (17.9\%).

Postoperative complications were identified in 12 patients $(8.2 \%)$. The types of postoperative complications are shown in Table II. Relevant clinicopathological characteristics of patients with and without postoperative complications are shown in Table III. Regarding host-related factors, the postoperative complication group had the presence of hemodialysis, psychiatric disorder, both with low SMA and high IMAC, low serum albumin level, high serum creatinine level and high CONUT score. Regarding surgical factors, the postoperative complication group had longer operation times 
Table I. Clinical characteristics of patients with hepatic resection.

\begin{tabular}{|c|c|c|}
\hline \multirow{2}{*}{$\frac{\text { Factors }}{\text { Age (years) }}$} & \multicolumn{2}{|c|}{ Value or number of patients $(n=146)$} \\
\hline & Median 68 & Range 28-89 \\
\hline Gender (Male/Female) & $106 / 40$ & \\
\hline BMI $\left(\mathrm{kg} / \mathrm{m}^{2}\right)$ & Median 22.7 & Range $14.8-31.4$ \\
\hline $\mathrm{NBNC} / \mathrm{HBV} / \mathrm{HCV}$ & $108 / 22 / 16$ & \\
\hline Diabetes mellitus & $32(21.9 \%)$ & \\
\hline Hemodialysis & $3(2.1 \%)$ & \\
\hline Brain infarction or bleeding & $9(6.1 \%)$ & \\
\hline Ischemic heart disease & $9(6.1 \%)$ & \\
\hline Respiratory disorder & $10(6.8 \%)$ & \\
\hline Psychiatric disorder & $9(6.1 \%)$ & \\
\hline Anti-coagulant or -platelet therapy & $17(11.6 \%)$ & \\
\hline Steroid use & $3(2.1 \%)$ & \\
\hline $\operatorname{SMA}\left(\mathrm{cm}^{2} / \mathrm{m}^{2}\right)$ & Median 36.8 & Range 20.9-58.4 \\
\hline IMAC & Median -0.60 & Range $-1.25--0.27$ \\
\hline Albumin $(\mathrm{g} / \mathrm{dl})$ & Median 4.1 & Range 2.6-5.1 \\
\hline Total bilirubin (mg/dl) & Median 0.7 & Range $0.3-27.8$ \\
\hline Platelet count $\left(10^{4} / \mu \mathrm{l}\right)$ & Median 17.7 & Range 3.5-28.4 \\
\hline Creatinine (mg/dl) & Median 0.76 & Range $0.38-9.01$ \\
\hline ICGR $15(\%)$ & Median 13.1 & Range $1.5-60.4$ \\
\hline CONUT score & Median 2 & Range $0-8$ \\
\hline Child A/B & $141 / 5$ & \\
\hline Liver cirrhosis $(\mathrm{F} 3+\mathrm{F} 4)$ & $12(8.2 \%)$ & \\
\hline \multirow[t]{4}{*}{ Disease } & HCC $55(37.6 \%)$ & \\
\hline & ICC $13(8.9 \%)$ & \\
\hline & Metastatic $66(45.2 \%)$ & \\
\hline & biliary tract cancer $12(8.2 \%)$ & \\
\hline Tumor size $(\mathrm{cm})$ & Median 2.6 & Range $0.7-16$ \\
\hline Solitary/multiple & $110 / 36$ & \\
\hline \multirow[t]{4}{*}{ Surgical procedure } & Lobectomy $45(30.8 \%)$ & \\
\hline & Segmentectomy $17(11.6 \%)$ & \\
\hline & Subsegmentectomy $20(13.7 \%)$ & \\
\hline & Partial $64(43.8 \%)$ & \\
\hline Operation time (min) & Median 368 & Range 128-682 \\
\hline Blood loss $(\mathrm{g})$ & Median 167 & Range 0-2994 \\
\hline Blood transfusion & $7(4.8 \%)$ & \\
\hline
\end{tabular}

HBV: Hepatitis B antigen-positive; HCV: Hepatitis C antibody-positive; SMA: smooth muscle area; IMAC: intramuscular adipose tissue; CONUT: controlling nutrition status; HCC: hepatocellular carcinoma; ICC: intrahepatic cholangiocarcinoma.

and greater blood loss than patients without complications. The mean length of hospital stay was significantly longer in patients with postoperative complications.

Relevant clinicopathological characteristics of patients with and without low SMA and high IMAC are shown in Table IV. The mean length of hospital stay was significantly longer in patients with both high IMAC and low SMA. Postoperative complications were identified in 7 cases among 39 patients with sarcopenia (17.9\%). There were no significant differences except for sex between patients with and without low SMA and high IMAC.

The results of the logistic regression analysis are shown in Table V: the presence of psychiatric disorder, hemodialysis,
Table II. Type of postoperative complication over Dindo-Clavien complication grade III.

No. of patients $(\%)$

$\begin{array}{ll}\text { Bile leakage } & 4(2.7) \\ \text { Ascites or pleural effusion } & 2(1.4) \\ \text { Pneumonia } & 2(1.4) \\ \text { Intra-abdominal abscess } & 1(0.7) \\ \text { Brain infarction } & 1(0.7) \\ \text { Obstruction of blood dialysis shunt } & 1(0.7) \\ \text { Re-intubation due to delayed awakening from anesthesia } & 1(0.7)\end{array}$

Total

$12(8.2 \%)$ 
Table III. Comparison of the clinicopathological factors between the two groups classified by postoperative complication.

\begin{tabular}{|c|c|c|c|}
\hline Variables & $\begin{array}{l}\text { Without complication } \\
\qquad(\mathrm{n}=134)\end{array}$ & $\begin{array}{l}\text { With complication } \\
\qquad(\mathrm{n}=12)\end{array}$ & $p$-Value \\
\hline \multicolumn{4}{|l|}{ Host related factor } \\
\hline Age & $66.9 \pm 11.8$ & $70.3 \pm 8.8$ & 0.34 \\
\hline High aged $(\geq 80)$ & $10(7.8 \%)$ & $2(11.1 \%)$ & 0.64 \\
\hline Male/Female & $96 / 38$ & $10 / 2$ & 0.51 \\
\hline $\mathrm{HBV}$ & $19(14.2 \%)$ & $2(13.3 \%)$ & 0.81 \\
\hline $\mathrm{HCV}$ & $22(16.4 \%)$ & $4(33.3 \%)$ & 0.14 \\
\hline Body mass index $\left(\mathrm{kg} / \mathrm{m}^{2}\right)$ & $22.6 \pm 3.1$ & $22.0 \pm 2.4$ & 0.57 \\
\hline Comobidity & $52(38.8 \%)$ & $8(66.7 \%)$ & 0.06 \\
\hline Diabetes mellitus & $28(20.9 \%)$ & $4(33.3 \%)$ & 0.29 \\
\hline Hemodialysis & $1(0.8 \%)$ & $2(16.7 \%)$ & 0.02 \\
\hline Brain infarction or bleeding & $9(6.7 \%)$ & $0(0 \%)$ & 0.45 \\
\hline Ischemic heart disease & $9(6.7 \%)$ & $0(0 \%)$ & 0.45 \\
\hline Respiratory disorder & $9(6.7 \%)$ & $1(8.3 \%)$ & 0.59 \\
\hline Psychiatric disorder & $6(4.5 \%)$ & $3(25.0 \%)$ & 0.03 \\
\hline Anti-coagulant or -platelet therapy & $17(12.7 \%)$ & $0(0 \%)$ & 0.36 \\
\hline Steroid use & $3(2.2 \%)$ & $0(0 \%)$ & 0.77 \\
\hline $\operatorname{SMA}\left(\mathrm{cm}^{2} / \mathrm{m}^{2}\right)$ & $37.5 \pm 7.6$ & $36.9 \pm 7.1$ & 0.80 \\
\hline IMAC & $-0.64 \pm 0.16$ & $-0.66 \pm 0.17$ & 0.67 \\
\hline with high IMAC and low SMA & $32(23.9 \%)$ & $7(58.3 \%)$ & 0.02 \\
\hline Albumin (g/dl) & $4.0 \pm 0.4$ & $3.8 \pm 0.5$ & 0.03 \\
\hline Total bilirubin (mg/dl) & $1.0 \pm 2.3$ & $0.9 \pm 0.3$ & 0.90 \\
\hline Platelet count $\left(10^{4} / \mu \mathrm{l}\right)$ & $20.8 \pm 2.0$ & $17.6 \pm 6.7$ & 0.64 \\
\hline Creatinine (mg/dl) & $0.8 \pm 0.2$ & $2.0 \pm 2.9$ & $<0.01$ \\
\hline ICGR15(\%) & $14.1 \pm 8.6$ & $11.7 \pm 7.3$ & 0.82 \\
\hline CONUT score & $1.9 \pm 1.4$ & $2.8 \pm 1.7$ & 0.03 \\
\hline Child-Pugh A/B & $131 / 3$ & $10 / 2$ & 0.05 \\
\hline Fibrosis $(\mathrm{F} 0,1,2 / 3,4)$ & $10(8.6 \%)$ & $2(6.7 \%)$ & 0.72 \\
\hline \multicolumn{4}{|l|}{ Tumor related factor } \\
\hline $\mathrm{HCC} / \mathrm{CCC} /$ metastasis/biliary & $46 / 12 / 64 / 12$ & $9 / 1 / 2 / 0$ & 0.24 \\
\hline Tumor size $(\mathrm{cm})$ & $3.6 \pm 2.9$ & $4.2 \pm 3.0$ & 0.53 \\
\hline Solitary/multiple & $101 / 33$ & $9 / 3$ & 0.97 \\
\hline \multicolumn{4}{|l|}{ Surgical factor } \\
\hline Operation time $(\mathrm{min})$ & $372 \pm 116$ & $438 \pm 97$ & 0.03 \\
\hline Blood loss (g) & $277 \pm 437$ & $538 \pm 625$ & 0.03 \\
\hline Transfusion (+) & $7(5.2 \%)$ & $0(0 \%)$ & 0.54 \\
\hline Anatomical/non-anatomical & $76 / 58$ & $6 / 6$ & 0.76 \\
\hline Hospital stay (day) & $12 \pm 5$ & $57 \pm 51$ & $<0.01$ \\
\hline Hospital death & 0 & 0 & - \\
\hline
\end{tabular}

Data are expressed as means \pm standard deviations or number of patients (percentage) as appropriate. HBV: Hepatitis B antigen-positive; HCV: Hepatitis C antibody-positive; SMA: skeletal muscle area; IMAC: intramuscular adipose tissue content; ICGR15: indocyanine green dye retention test at $15 \mathrm{~min}$; CONUT: controlling nutritional status, HCC: hepatocellular carcinoma; CCC: cholangiocellular carcinoma; Metastatic: metastatic liver cancer; biliary: biliary cancer.

low SMA and high IMAC and high CONUT score were independent predictors of occurrence of postoperative complications.

\section{Discussion}

According to multivariate analysis, in this retrospective study, the presence of psychiatric disorder, hemodialysis, low SMA and high IMAC and high CONUT score were independent predictors of occurrence of postoperative complications in patients with hepatic resection for hepatic malignancies.

Mavros et al. reported that postoperative complications classified as Clavien-Dindo grade III or more were identified in $5.6 \%$ of patients and were independently associated with decreased long-term survival after surgery for colorectal liver metastases (7). Postoperative complications were significantly 
Table IV. Comparison of the clinicopathological factors between the two groups classified by the status of IMAC and SMA.

\begin{tabular}{|c|c|c|c|}
\hline Variables & $\begin{array}{l}\text { Without high IMAC } \\
\text { and low SMA } \\
(n=107)\end{array}$ & $\begin{array}{l}\text { With high IMAC } \\
\text { and low SMA } \\
\quad(n=39)\end{array}$ & $p$-Value \\
\hline \multicolumn{4}{|l|}{ Host related factor } \\
\hline Age & $67.2 \pm 11.6$ & $67.1 \pm 11.4$ & 0.96 \\
\hline High aged $(\geq 80)$ & $14(13.1 \%)$ & $4(10.3 \%)$ & 0.78 \\
\hline Male/Female & $72 / 35$ & $34 / 5$ & 0.02 \\
\hline HBV & $18(16.8 \%)$ & $2(5.1 \%)$ & 0.10 \\
\hline $\mathrm{HCV}$ & $18(16.8 \%)$ & $10(25.6 \%)$ & 0.24 \\
\hline Body mass index $\left(\mathrm{kg} / \mathrm{m}^{2}\right)$ & $22.6 \pm 3.4$ & $22.3 \pm 2.1$ & 0.57 \\
\hline Comorbidity & $43(40.2 \%)$ & $17(43.6 \%)$ & 0.71 \\
\hline Diabetes mellitus & $23(21.5 \%)$ & $9(23.1 \%)$ & 0.82 \\
\hline Hemodialysis & $2(1.9 \%)$ & $1(2.6 \%)$ & 0.87 \\
\hline Brain infarction or bleeding & $7(6.5 \%)$ & $2(5.1 \%)$ & 0.88 \\
\hline Ischemic heart disease & $9(8.4 \%)$ & $0(0 \%)$ & 0.11 \\
\hline Respiratory disorder & $8(6.7 \%)$ & $2(5.1 \%)$ & 0.80 \\
\hline Psychiatric disorder & $6(5.6 \%)$ & $3(7.7 \%)$ & 0.71 \\
\hline Anti-coagulant or -platelet therapy & $15(14.0 \%)$ & $2(5.1 \%)$ & 0.24 \\
\hline Steroid use & $3(2.8 \%)$ & $0(0 \%)$ & 0.56 \\
\hline $\operatorname{SMA}\left(\mathrm{cm}^{2} / \mathrm{m}^{2}\right)$ & $38.3 \pm 8.1$ & $35.2 \pm 5.1$ & 0.02 \\
\hline IMAC & $-0.68 \pm 0.16$ & $-0.53 \pm 0.1$ & 0.01 \\
\hline Albumin (g/dl) & $4.1 \pm 0.4$ & $3.9 \pm 0.5$ & 0.11 \\
\hline Total bilirubin (mg/dl) & $1.0 \pm 0.2$ & $0.8 \pm 0.5$ & 0.66 \\
\hline Platelet count $\left(10^{4} / \mu \mathrm{l}\right)$ & $21.1 \pm 26.6$ & $19.2 \pm 8.5$ & 0.65 \\
\hline Creatinine (mg/dl) & $0.9 \pm 0.8$ & $0.9 \pm 1.1$ & 0.58 \\
\hline ICGR15(\%) & $13.6 \pm 8.5$ & $14.7 \pm 8.5$ & 0.53 \\
\hline CONUT score & $1.9 \pm 1.4$ & $1.9 \pm 1.4$ & 0.88 \\
\hline Child-Pugh A/B & $105 / 2$ & $36 / 3$ & 0.11 \\
\hline Fibrosis(F0,1,2/3,4) & $23(21.5 \%)$ & $7(23.3 \%)$ & 0.82 \\
\hline \multicolumn{4}{|l|}{ Tumor related factor } \\
\hline $\mathrm{HCC} / \mathrm{CCC} /$ metastatic/biliary & $40 / 10 / 48 / 9$ & $15 / 3 / 16 / 3$ & 0.60 \\
\hline Tumor size $(\mathrm{cm})$ & $3.6 \pm 2.9$ & $4.2 \pm 3.0$ & 0.53 \\
\hline Solitary/multiple & $101 / 33$ & $9 / 3$ & 0.97 \\
\hline \multicolumn{4}{|l|}{ Surgical factor } \\
\hline Operation time (min) & $366 \pm 11$ & $409 \pm 18$ & 0.05 \\
\hline Blood loss (g) & $297 \pm 496$ & $302 \pm 341$ & 0.95 \\
\hline Transfusion (+) & $7(6.5 \%)$ & $0(0 \%)$ & 0.19 \\
\hline Anatomical/non-anatomical & $59 / 48$ & $23 / 16$ & 0.71 \\
\hline Postoperative complications & $5(4.7 \%)$ & $7(17.9 \%)$ & 0.02 \\
\hline Hospital stay (day) & $14 \pm 11$ & $20 \pm 32$ & 0.02 \\
\hline Hospital death & $0(0 \%)$ & $0(0 \%)$ & - \\
\hline
\end{tabular}

Data are expressed as means \pm standard deviations or number of patients (percentage) as appropriate. HBV: Hepatitis B antigen-positive; HCV: Hepatitis C antibody-positive; SMA: skeletal muscle area; IMAC: intramuscular adipose tissue content; ICGR15: indocyanine green dye retention test at $15 \mathrm{~min}$; CONUT: controlling nutritional status; HCC: hepatocellular carcinoma; CCC: cholangiocellular carcinoma; Metastatic: metastatic liver cancer; biliary: biliary cancer.

predictive of a worse overall survival, even when adjustments are made for other known predictors in patients who had undergone hepatic resection for hepatocellular carcinoma at some high-volume institutions (2). Postoperative complication will be important oncologically.

The quality of skeletal muscle was not clearly defined to this day. We previously reported that patients with both low skeletal muscle mass and function had significantly worse liver function, greater estimated blood loss, greater incidence of severe postoperative complications and longer postoperative hospital stay (17), however measuring skeletal muscle quality is difficult because hand grip or gait speed have to be measured prospectively. On the other hand, measuring IMAC is easily performed retrospectively. Van 
Table V. Logistic regression of predictive factor for the occurrence of postoperative complication.

\begin{tabular}{lccc}
\hline Variables & $\begin{array}{c}\text { Odd's } \\
\text { ratio }\end{array}$ & $\begin{array}{c}5 \% \text { confidence } \\
\text { interval }\end{array}$ & $p$-Value \\
\hline Psychiatric disorder & 1.83 & $2.36-16.69$ & 0.01 \\
Hemodialysis & 3.94 & $2.29-13.56$ & 0.01 \\
High IMAC and low SMA & 6.12 & $1.44-32.60$ & 0.01 \\
High CONUT score & 1.69 & $1.02-2.85$ & 0.04 \\
\hline
\end{tabular}

SMA: Skeletal muscle area; IMAC: intramuscular adipose tissue content; CONUT: controlling nutritional status.

Rijssen LB reported that in patients undergoing pancreaticduodenectomy for periampullary and non-pancreatic cancer, low muscle quality was independently associated with decreased survival and an increased incidence of major postoperative complications (19). They measured the skeletal muscle attenuation index which was calculated by measuring the average HUs of the total muscle area at the L3 level. Also, Hamaguchi $\mathrm{Y}$ and Kaibori $\mathrm{M}$ et al. reported high IMAC, which means greater fat accumulation in skeletal muscle, was predictive of worse overall survival after hepatic resection in patients with $\operatorname{HCC}(11,18)$. Additionally, on multivariate analysis, preoperative high IMAC was an independent risk factor for increased major postoperative complications and infectious complications (10). Muscle steatosis is associated to insulin resistance (27), but the detailed mechanism is not clear. Lipid accumulation to muscle is reported to be associated with hepatic insulin resistance and lead to lipid accumulation in the liver, which means liver dysfunction (28). Skeletal muscle is the organ which secrete many growth factors and cytokines (29). The mechanisms of secreted factor for liver function need to be clarified in the future.

Evaluating preoperative comorbidity is important for predicting postoperative complications. Patients undergoing hemodialysis are reported to have a substantially increased risk of mortality and morbidity after hepatic resection according to the national database in Japan (30). Toshima et $a l$. reported that massive effusion was significantly higher in patients with renal dysfunction after hepatic resection for HCC (31). The surgical mortality in psychiatric populations was reported to be higher than in a comparable non-psychiatric population (32), although on the other hand patients with psychiatric disorders are not accompanied with excess surgical risk during major surgery for digestive malignancies compared to patients without psychiatric disorders (33). Further studies in larger patient populations are required.

CONUT score, which is an objective tool that is widely used to assess the nutritional status in patients, is reported to be useful for predicting the prognosis of HCC after hepatic resection (24). CONUT score is also reported to be associated with postoperative complications in many cancers $(34,35)$.

This retrospective analysis showed that the presence of psychiatric disorder, hemodialysis, low SMA and high IMAC and high CONUT score were independent predictors of occurrence of postoperative complications in patients undergoing hepatic resection for hepatic malignancies. Intensive surgical care is necessary for these high-risk patients. Low skeletal muscle mass plus high muscle steatosis is a candidate for preoperative nutrition and rehabilitation.

\section{Conflicts of Interest}

All Authors declare no conflicts of interest.

\section{References}

1 Shimada M, Takenaka K, Fujiwara Y, Gion T, Shirabe K, Yanaga $\mathrm{K}$ and Sugimachi K: Risk factors linked to postoperative morbidity in patients with hepatocellular carcinoma. Br J Surg 85: 195-198, 1998.

2 Harimoto N, Shirabe K, Ikegami T, Yoshizumi T, Maeda T, Kajiyama K, Yamanaka $\mathrm{T}$ and Maehara Y: Postoperative complications are predictive of poor prognosis in hepatocellular carcinoma. J Surg Res 199(2): 470-477, 2015.

3 Taketomi A, Kitagawa D, Itoh S, Harimoto N, Yamashita Y, Gion T, Shirabe K, Shimada M and Maehara Y: Trends in morbidity and mortality after hepatic resection for hepatocellular carcinoma: an institute's experience with 625 patients. J Am Coll Surg 204(4): 580-587, 2007.

4 Fan ST, Lo CM, Liu CL, Lam CM, Yuen WK, Yeung C and Wong J: Hepatectomy for hepatocellular carcinoma: toward zero hospital deaths. Ann Surg 229(3): 322-330, 1999.

5 Chok KS, Ng KK, Poon RT, Lo CM and Fan ST: Impact of postoperative complications on long-term outcome of curative resection for hepatocellular carcinoma. Br J Surg 96(1): 81-87, 2009.

6 Law WL, Choi HK, Lee YM and Ho JW: The impact of postoperative complications on long-term outcomes following curative resection for colorectal cancer. Ann Surg Oncol 14(9): 2559-2566, 2007.

7 Mavros MN, de Jong M, Dogeas E, Hyder O and Pawlik TM: Impact of complications on long-term survival after resection of colorectal liver metastases. Br J Surg 100(5): 711-718, 2013.

8 Harimoto N, Shirabe K, Yamashita Y, Ikegami T, Yoshizumi T, Soejima Y, Ikeda T, Maehara Y, Nishie A and Yamanaka T: Sarcopenia is predictive of poor prognosis in patients with hepatocellular carcinoma after hepatectomy. Br J Surg 100(11): 1523-1530, 2013.

9 van Vledder MG, Levolger S, Ayez N, Verhoef C, Tran TC and Ijzermans JN: Body composition and outcome in patients undergoing resection of colorectal liver metastases. Br J Surg 99(4): 550-557, 2012.

10 Hamaguchi Y, Kaido T, Okumura S, Kobayashi A, Fujimoto Y, Ogawa K, Mori A, Hammad A, Hatano E and Uemoto S: Muscle steatosis is an independent predictor of postoperative complications in patients with hepatocellular carcinoma. World J Surg 40(8): 1959-1968, 2016. 
11 Hamaguchi Y, Kaido T, Okumura S, Ito T, Fujimoto Y, Ogawa K, Mori A, Hammad A, Hatano E and Uemoto S: Preoperative intramuscular adipose tissue content is a novel prognostic predictor after hepatectomy for hepatocellular carcinoma. J Hepatobiliary Pancreat Sci 22(6): 475-485, 2015.

12 Okumura S, Kaido T, Hamaguchi Y, Fujimoto Y, Kobayashi A, Iida T, Yagi S, Taura K, Hatano E and Uemoto S: Impact of the preoperative quantity and quality of skeletal muscle on outcomes after resection of extrahepatic biliary malignancies. Surgery 159(3): 821-833, 2016.

13 Okumura S, Kaido T, Hamaguchi Y, Fujimoto Y, Masui T, Mizumoto M, Hammad A, Mori A, Takaori K and Uemoto S: Impact of preoperative quality as well as quantity of skeletal muscle on survival after resection of pancreatic cancer. Surgery 157(6): 1088-1098, 2015.

14 Rosenberg I: Summary comments: epidemiological and methodological problems in determining nutritional status of older persons. Am J Clin Nutr 50: 1231-1233, 1989.

15 Baumgartner RN, Koehler KM, Gallagher D, Romero L, Heymsfield SB, Ross RR, Garry PJ and Lindeman RD: Epidemiology of sarcopenia among the elderly in New Mexico. Am J Epidemiol 147: 755-763, 1998.

16 Cruz-Jentoft AJ, Baeyens JP, Bauer JM, Boirie Y, Cederholm T, Landi F, Martin FC, Michel JP, Rolland Y, Schneider SM, Topinková E, Vandewoude $\mathrm{M}$ and Zamboni M; European Working Group on Sarcopenia in Older People: European Working Group on Sarcopenia in Older People. Sarcopenia: European consensus on definition and diagnosis: Report of the European Working Group on Sarcopenia in Older People. Age Ageing 39(4): 412-423, 2010.

17 Harimoto N, Yoshizumi T, Izumi T, Motomura T, Harada N, Itoh S, Ikegami T, Uchiyama H, Soejima Y, Nishie A, Kamishima T, Kusaba R, Shirabe K and Maehara Y: Clinical outcomes of living liver transplantation according to the presence of sarcopenia as defined by skeletal muscle mass, hand grip, and gait speed. Transplant Proc 49(9): 2144-2152, 2017.

18 Kaibori M, Ishizaki M, Iida H, Matsui K, Sakaguchi T, Inoue K, Mizuta T, Ide Y, Iwasaka J, Kimura Y, Hayashi F, Habu D and Kon M: Effect of intramuscular adipose tissue content on prognosis in patients undergoing hepatocellular carcinoma resection. J Gastrointest Surg 19(7): 1315-1323, 2015.

19 Van Rijssen LB, van Huijgevoort NC, Coelen RJ, Tol JA, Haverkort EB, Nio CY, Busch OR and Besselink MG: Skeletal muscle quality is associated with worse survival after pancreatoduodenectomy for periampullary, nonpancreatic cancer. Ann Surg Oncol 24(1): 272-280, 2017.

20 Addison O, Marcus RL, Lastayo PC and Ryan AS: Intermuscular fat: a review of the consequences and causes. Int J Endocrinol 2014: 309570, 2014

21 Dindo D, Demartines N and Clavien PA: Classification of surgical complications: a new proposal with evaluation in a cohort of 6336 patients and results of a survey. Ann Surg 240(2): 205-213, 2004.

22 Nishikawa H, Shiraki M, Hiramatsu A, Moriya K, Hino K and Nishiguchi S: Japan Society of Hepatology guidelines for sarcopenia in liver disease (1st edition): Recommendation from the working group for creation of sarcopenia assessment criteria. Hepatol Res 46(10): 951-963, 2016.

23 de Ulibarri Perez JI, Gonzalez-Madrono A, de Villar NG, Gonzalez P, Gonzalez B, Mancha A, Rodríguez F and Fernández
G: CONUT: A tool for Controlling Nutritional Status. First validation in a hospital population. Nutr Hosp 20: 38-45, 2005.

24 Harimoto N, Yoshizumi T, Sakata K, Nagatsu A, Motomura T, Itoh S, Harada N, Ikegami T, Uchiyama H, Soejima Y and Maehara Y: Prognostic significance of preoperative controlling nutritional status (CONUT) score in patients undergoing hepatic resection for hepatocellular carcinoma. World J Surg 41(11): 2805-2812, 2017.

25 Yamashita Y, Taketomi A, Itoh S, Kitagawa D, Kayashima H, Harimoto N, Tsujita E, Kuroda Y and Maehara Y: Long-term favorable results of limited hepatic resections for patients with hepatocellular carcinoma: 20 years of experience. J Am Coll Surg 205(1): 19-26, 2007.

26 Rahbari NN, Koch M, Mehabi A, Weidmann K, Motschall E, Kahlert C, Büchler MW and Weitz J: Portal triad clamping versus vascular exclusion for vascular control during hepatic resection: A systematic review and meta-analysis. J Gastrointest Surg 13: 558-568, 2009.

27 Brøns C and Grunnet LG: Mechanisms in endocrinology: Skeletal muscle lipotoxicity in insulin resistance and type 2 diabetes: a causal mechanism or an innocent bystander? Eur J Endocrinol 176(2): R67-R78, 2017.

28 Grunnet LG, Laurila E, Hansson O, Almgren P, Groop L, Brøns C, Poulsen P and Vaag A: The triglyceride content in skeletal muscle is associated with hepatic but not peripheral insulin resistance in elderly twins. J Clin Endocrinol Metab 97(12): 4571-4577, 2012.

29 Karalaki M, Fili S, Philippou A and Koutsilieris M: Muscle regeneration: cellular and molecular events. In Vivo 23(5): 779796, 2009.

30 Shinkawa H, Yasunaga H, Hasegawa K, Matsui H, Fushimi K, Michihata N and Kokudo N: Mortality and morbidity after hepatic resection in patients undergoing hemodialysis: analysis of a national inpatient database in Japan. Surgery 163(6): 1234-1237, 2018.

31 Toshima T, Shirabe K, Yoshiya S, Muto J, Ikegami T, Yoshizumi $\mathrm{T}$ and Maehara Y: Outcome of hepatectomy for hepatocellular carcinoma in patients with renal dysfunction. HPB (Oxford) 14(5): 317-324, 2012.

32 Tsuang MT and Woolson RF: Mortality in patients with schizophrenia, mania, depression and surgical condition. Br J Psychiatry 130: 162-166, 1977.

33 Aoyanagi N, Iizuka I and Watanabe M: Surgery for digestive malignancies in patients with psychiatric disorders. World J Surg 31(12): 2323-2328, 2007.

34 Yoshida N, Baba Y, Shigaki H, Harada K, Iwatsuki M, Kurashige J, Sakamoto Y, Miyamoto Y, Ishimoto T, Kosumi K, Tokunaga R, Imamura Y, Ida S, Hiyoshi Y, Watanabe M and Baba H: Preoperative nutritional assessment by controlling nutritional status (CONUT) is useful to estimate postoperative morbidity after esophagectomy for esophageal cancer. World J Surg 40(8): 1910-1917, 2016.

35 Tokunaga R, Sakamoto Y, Nakagawa S, Ohuchi M, Izumi D, Kosumi K, Taki K, Higashi T, Miyamoto Y, Yoshida N, Oki E, Watanabe $\mathrm{M}$ and Baba H: CONUT: a novel independent predictive score for colorectal cancer patients undergoing potentially curative resection. Int J Colorectal Dis 32(1): 99-106, 2017.

Received June 4, 2018

Revised June 12, 2018

Accepted June 13, 2018 